LETTERS TO THE EDITOR

\section{IL-5 in asthma}

We have recently published two manuscripts on the effects of interleukin (IL)-5 administration to patients with mild asthma in the American Journal of Respiratory $\theta$ Critical Care Medicine $^{1}$ and in Thorax. ${ }^{2}$ We are addressing this letter to the Editors of both journals.

The data described in both papers have been obtained from one experiment performed in the same group of patients with mild asthma. While the paper in the American Journal of Respiratory of Critical Care Medicine reports primarily on the phenotypic changes in circulating blood eosinophils and CD34+ cells, the Thorax paper describes the changes in the airways with measurements of bronchial responsiveness and of eosinophil count in sputum, together with eotaxin levels in the serum. Both manuscripts, however, detail the changes in blood eosinophil counts and serum IL-5 changes derived from these nine patients, which constitutes a partial duplication of the data described in the two papers. At the time of submission of the manuscripts to the two journals we did not inform the respective journals of the existence and submission of the other manuscript.

We would also like to take the opportunity of pointing out one mistake and two differences in the two manuscripts:

(1) Table 1 in Thorax contains mistakes regarding the $\mathrm{FEV}_{1}$ values; table $\mathrm{l}$ in the $\mathrm{Am} J$ Respir Crit Care Med paper shows the correct values.

(2) The Am J Respir Crit Care Med paper quotes the median values in the text while mean values are plotted in fig 2, and the Thorax paper the geometric mean.

(3) The blood eosinophil counts were analysed in the Am J Respir Crit Care Med paper as paired $t$ tests while in the Thorax paper we used repeated measures analysis of variance (as recommended by a reviewer) which does not provide significant differences in eosinophil counts.

We recognise that it has been an error of judgement on our part in having the experimental data from this study reported in two separate manuscripts, and also in not informing you (and the reviewers) of the existence of

If you have a burning desire to respond to a paper published in Thorax, why not make use of our "rapid response" option?

Log on to our website (www.thoraxinl.com), find the paper that interests you, and send your response via email by clicking on the "eletters" option in the box at the top right hand corner.

Providing it isn't libellous or obscene, it will be posted within seven days. You can retrieve it by clicking on "read eletters" on our homepage.

The editors will decide as before whether to also publish it in a future paper issue. these two separate manuscripts at the time of submission. We have not intentionally set out to duplicate publication of our experimental data and regret that this has happened. We also would like to apologise for the concern that this may cause to the high reputation of both journals.

\section{K F Chung, E van Rensen, R Stirling,} P J Barnes

Department of Thoracic Medicine, National Heart and lung Institute Imperial College School of Medicine, London SW3 6LY, UK

\section{References}

1 Stirling RG, van Rensen EL, Barnes PJ, et al. Interleukin-5 induces CD34(+) eosinophil progenitor mobilization and eosinophil CCR3 expression in asthma. Am J Respir Crit Care Med 2001;164:1403-9.

2 Van Rensen ELJ, Stirling RG, Scheerens J, et al. Evidence for systemic rather than pulmonary effects of interleukin-5 administration in asthma. Thorax 2001;56:935-40

\section{Bronchoconstrictor effect of deep inspiration in asthma}

I was interested in the article by Burns and Gibson in the February issue of Thorax, ${ }^{1}$ but feel that the authors should exclude the following possible confounding factors which should be addressed before their hypothesis can be accepted.

(1) The time course of the bronchoconstrictor response to deep breaths in mild asthma is brief (usually 60-90 seconds), so the precise timing of the sGaw measurements after the manoeuvre is critical. Have the authors taken this into consideration?

(2) Although the pre-test and test breathing pattern was standardised as far as possible, have changes in $\mathrm{PCO}_{2}$ been excluded since hypocapnia can have a larger effect on sGaw even in normal subjects than that described here.

(3) Why do their normal subjects show a fall from baseline sGaw after deep breaths rather than the consistent small rise seen in previous studies as quoted in the discussion?

If these points can be answered, then further investigation of their inherently speculative hypothesis might indeed be worthwhile.

Consultant Physician Emeritus, Vermont House, Withers Lane, East Boldre, Brockenhurst, Hampshire SO42 7WX, UK

\section{References}

Burns GP, Gibson, GJ. A novel hypothesis to explain the bronchoconstrictor effect of deep inspiration in asthma. Thorax 2002:57: 116-9

2 Sterling GM. The mechanism of bronchoconstriction due to hypocapnia in man. Clin Sci 1968;34:272-85.

\section{Authors' reply}

We agree with Dr Sterling that the bronchoconstrictor effect of a deep inspiration in asthma is brief and that the timing of the sGaw measurement is critical. The relevant comparison is between the sGaw performed after the timed non-forced inspiratory manoeuvres and that performed after the forced inspiratory manoeuvres. In each case, as stated in our paper, subjects returned to functional residual capacity (FRC) immediately after the final full inspiration, ensuring both parity in the timing of the two manoeuvres and that in each case sGaw was measured as soon as practically possible after the inspiration.

$\mathrm{PCO}_{2}$ was not measured but the inspiratory/ expiratory manoeuvres preceding the measurement of sGaw were designed to be identical in their time-volume relationship. This was in order to minimise any difference in the behaviour of the smooth muscle (or any other element responsive to stretch), but it would, of course, also ensure that any difference in ventilation, and thus $\mathrm{PCO}_{2}$, was also minimised.

We compared sGaw after two different types of inspiratory manoeuvre which were designed to be identical in every respect other than the intrathoracic pressure generated. The constraints of this requirement meant that the inspiratory manoeuvres were different from the usual rapid deep inspiration preceding the measurement of sGaw in the referenced studies. The longer inspiratory manoeuvre in our study would be expected to produce a significantly diminished bronchodilating effect than that produced by the usual rapid deep inspiration. ${ }^{2}$ This probably explains the absence of any significant difference between the baseline sGaw (before deep inspiration) and that performed after deep inspiration (without resistance) in healthy subjects.

G J Gibson, G P Burns

Department of Respiratory Medicine, Freeman Hospital, High Heaton, Newcastle upon Tyne NE7 7DN, UK; g.j.gibson@ncl.ac.uk

\section{References}

1 Burns GP, Gibson GJ. A novel hypothesis to explain the bronchoconstrictor effect of deep inspiration in asthma. Thorax 2002:57: 116-9.

2 Wanger JS, Ikle DN, Cherniack RM. The effect of inspiratory maneuvers on expiratory flow rates in health and asthma: influence of lung elastic recoil. Am J Respir Crit Care Med 1996;153:1302-8.

\section{Inhaled sodium cromoglycate in children with asthma}

We admire the perseverence of Dr Edwards and colleagues to dispute the conclusions of our systematic review on sodium cromoglycate in asthmatic children. ${ }^{12}$ We note that they restrict their present comments to only a single point-interpretation of the tolerance interval. In fact, our conclusions were based not only on this finding but also on the apparent publication bias and the small overall treatment effect. Hence, we stick to our conclusion that there is insufficient evidence that maintenance treatment with sodium cromoglycate is beneficial in children with asthma.

M J A Tasche, J H J M Uijen, R M D Bernsen, J C de Jongste, J C van der Wouden

Department of General Practice and Division of Pediatric Respiratory Medicine, Erasmus University Medical Center, Rotterdam, The Netherlands: vanderwouden@hag.fgg.eur.nl 


\section{References}

1 Edwards A, Stevens M, Holgate S, et al. Inhaled sodium cromoglycate in children with asthma (letter). Thorax 2002 $57 \cdot 282$

2 Tasche MJA, Uijen JHJM, Bernsen RMD, et al. Inhaled disodium cromoglycate (DSCG) as maintenance therapy in children with asthma: a systematic review. Thorax 2000;55:913-20.

\section{Body mass index and asthma}

We read with interest the report by von Mutius et al on the association between body mass index (BMI) and asthma in children. The finding that the association between asthma and obesity may be mediated by mechanical factors or by an alternative inflammatory mechanism rather than eosinophilic inflammation is important and contributes to our understanding of the causal pathway.

With regard to breastfeeding, the authors state: "Breast feeding was no longer a significant predictor of asthma once BMI was introduced into the model. However, this may be because the intermediate variable (BMI) was introduced in the model." The authors then surmise that BMI is an independent variable, and the results of their multivariate analyses-including breastfeeding-do not support the notion that "BMI might be an intermediate step". However, if the former is correct, then lack of breastfeeding is the problem and a reduction of BMI may not reduce asthma, as claimed by the authors. The conclusions drawn appear to be contradictory and also do not reflect the limitations of cross sectional analyses.

The question is whether: (1) lack of breastfeeding results in increased BMI and increased BMI is an intermediate step in the aetiology of asthma; or (2) the association between BMI and asthma is a spurious correlation and both are caused by lack of breastfeeding; or (3) both increased BMI and shortened breastfeeding are independent risk factors.
Acknowledging the restriction of cross sectional analyses, the authors need to clarify their conclusions and provide the respective models and path (or partial) coefficients that support one or other of the models suggested above.

I Eneli

Department of Pediatrics/Human Development, Michigan State University, Michigan State University, East Lansing, MI 48823, USA

W Karmaus

Department of Epidemiology, Michigan State University, East Lansing, MI 48823, USA karmaus@msu.edu

\section{Reference}

1 von Mutius E, Schwartz J, Neas LM, et al. Relation of body mass index to asthma and atopy in children: the National Health and Nutrition Examination Study III. Thorax $2001 ; 56: 835-8$.

\section{BOOK REVIEW}

\section{Pulmonary Physiology and Pathophysiology}

J B West. Lippincott Williams \& Wilkins, 2000. \$31.95. ISBN 0781729106

John West's classic texts Respiratory Physiology: The Essentials and Pulmonary Pathophysiology: The Essentials are read by almost all respiratory medicine specialists at some stage of their training. This new book is aimed at medical students. It condenses both into one volume and adopts a case based approach. Each chapter opens with a clinical vignette to introduce a physiological topic. While this might appear attractive in placing the physiology in a clinical context, abandoning the clear and logical route taken by the previous volumes does make the new book very hard work to read. In the first chapter we meet a competitive cyclist and, before the end of the first page, we are on to her exercise test results and discussing anaerobic thresholds. After the inevitable mountaineering trip in chapter 2 , subsequen chapters start with the stories of patients with COPD, asthma, pulmonary fibrosis, pulmonary embolism, pulmonary oedema, pneumoconiosis, and ARDS. Some of the chapters work well; others feel as if several different sections of the previous books have been pasted together between a case history to start and an extract from a textbook of clinical respiratory medicine to end. Nevertheless, this book contains a wealth of material and will repay careful study by those adopting a case based approach to medicine. For my money, I would start with Respiratory Physiology: The Essentials, even though it costs about the same as the new two-in-one integrated version.

W Kinnear

\section{NOTICE}

\section{6th International Mesothelioma \\ Conference}

The 6th Conference of the International Mesothelioma Interest Group will be held at the Queen Elizabeth II Medical Centre, Perth, Western Australia on 1-3 December 2002. For further information contact Mrs Maree Branigan, University Department of Medicine, 4th Floor, G Block, QEII Medical Centre, Verdun Street, Nedlands, Perth, Western Australia 6009; telephone +61 (0)8 9346 2005, fax +61 (0) 89346 2816, e-mail: branigan@cyllene.uwa.edu.au

\section{CORRECTION}

In the paper entitled "Effects of daily variation in outdoor particulates and ambient acid species in normal and asthmatic children" by D J Ward et al which appeared in the June issue of Thorax (2002;57:489-502), the first sentence in the Conclusion of the abstract should have read: "These data do not suggest that adverse health outcomes are associated with daily variations in pollutants". We apologise for this error. 